\title{
Physiogenomic analysis of weight loss induced by dietary carbohydrate restriction
} Gualberto Ruaño*1, Andreas Windemuth11, Mohan Kocherla1, Theodore Holford ${ }^{2}$, Maria Luz Fernandez ${ }^{3}$, Cassandra E Forsythe ${ }^{4}$, Richard J Wood ${ }^{3}$, William J Kraemer ${ }^{4}$ and Jeff S Volek ${ }^{4}$

Address: ${ }^{1}$ Genomas, Inc., 67 Jefferson St, Hartford, CT 06106, USA, ${ }^{2}$ Department of Biostatistics, Yale University School of Medicine, New Haven, CT 06520, USA, ${ }^{3}$ Department of Nutritional Sciences, University of Connecticut, Storrs, CT 06269, USA and ${ }^{4}$ Human Performance Laboratory, Department of Kinesiology, University of Connecticut, Storrs, CT 06269, USA

Email: Gualberto Ruaño* - g.ruano@genomas.net; Andreas Windemuth - a.windemuth@genomas.net;

Mohan Kocherla - m.kocherla@genomas.net; Theodore Holford - theodore.holford@yale.edu; Maria Luz Fernandez - maria-

luz.fernandez@uconn.edu; Cassandra E Forsythe - Cassandra.forsythe@uconn.edu; Richard J Wood - richard.wood@uconn.edu;

William J Kraemer - william.kraemer@uconn.edu; Jeff S Volek - jeff.volek@uconn.edu

* Corresponding author

\section{Published: 15 May 2006}

Nutrition \& Metabolism 2006, 3:20 doi:10.1 186/1743-7075-3-20
Received: 06 March 2006

Accepted: 15 May 2006

This article is available from: http://www.nutritionandmetabolism.com/content/3/I/20

(c) 2006 Ruaño et al; licensee BioMed Central Ltd.

This is an Open Access article distributed under the terms of the Creative Commons Attribution License (http://creativecommons.org/licenses/by/2.0), which permits unrestricted use, distribution, and reproduction in any medium, provided the original work is properly cited.

\begin{abstract}
Background: Diets that restrict carbohydrate $(\mathrm{CHO})$ have proven to be a successful dietary treatment of obesity for many people, but the degree of weight loss varies across individuals. The extent to which genetic factors associate with the magnitude of weight loss induced by $\mathrm{CHO}$ restriction is unknown. We examined associations among polymorphisms in candidate genes and weight loss in order to understand the physiological factors influencing body weight responses to $\mathrm{CHO}$ restriction.

Methods: We screened for genetic associations with weight loss in 86 healthy adults who were instructed to restrict $\mathrm{CHO}$ to a level that induced a small level of ketosis $(\mathrm{CHO} \sim 10 \%$ of total energy). A total of 27 single nucleotide polymorphisms (SNPs) were selected from 15 candidate genes involved in fat digestion/metabolism, intracellular glucose metabolism, lipoprotein remodeling, and appetite regulation. Multiple linear regression was used to rank the SNPs according to probability of association, and the most significant associations were analyzed in greater detail.
\end{abstract}

Results: Mean weight loss was $6.4 \mathrm{~kg}$. SNPs in the gastric lipase (LIPF), hepatic glycogen synthase (GYS2), cholesteryl ester transfer protein (CETP) and galanin (GAL) genes were significantly associated with weight loss.

Conclusion: A strong association between weight loss induced by dietary $\mathrm{CHO}$ restriction and variability in genes regulating fat digestion, hepatic glucose metabolism, intravascular lipoprotein remodeling, and appetite were detected. These discoveries could provide clues to important physiologic adaptations underlying the body mass response to $\mathrm{CHO}$ restriction. 


\section{Introduction}

A first line of attack on diabetes and cardiovascular disease is a reduction in body mass. A consistent finding across many different diet studies is that carbohydrate $(\mathrm{CHO})$ restriction has a central role in facilitating weight loss and improving features of metabolic syndrome $[1,2]$, due to mechanisms related to metabolic efficiency $[3,4]$ and factors related to appetite regulation $[5,6]$.

Genetic factors interact with dietary nutrients to impact the development of obesity and the outcome of weight loss therapies. The etiology of obesity is complex and can result from a disruption in functioning of diverse but interconnected pathways. Researchers have shown that polymorphisms in several different genes play a role in determining weight loss or weight maintenance in response to various pharmacological and non-pharmacological therapies. The approach taken in these genetic studies has been to separate individuals based upon allelic variation is a candidate gene and determine if weight loss or better maintenance of body mass varies as a function of the polymorphism. For example, body mass responses to various therapies have been linked to genes coding for products involved in the sympathetic nervous system [7$11]$, appetite regulating hormones [12,13], adipose tissue transcription factors $[14,15]$, and proteins regulating fat digestion, deposition and mobilization [15-17].

In this study we use physiogenomics [18], a medical application of sensitivity analysis and systems engineering. Sensitivity analysis is the study of the relationship between input and output from a system as determined by each system component. Physiogenomics utilizes the genes as the components of the system. The gene variability, measured by single nucleotide polymorphisms (SNPs), is correlated to physiological responses of a population, the output. Physiogenomics determines how the SNP frequency varies among individuals similarly responding to the input over the entire range of the response distribution.

Scrutiny of weight loss responses for subjects who have consumed $\mathrm{CHO}$ restricted diets in our laboratory revealed a rather large amount of variability in the magnitude of weight loss $[19,20]$. This variability is not readily explained by standard covariates such as caloric intake, gender, age, activity, etc. Therefore a physiogenomic approach was undertaken using families of candidate genes, selected from those hypothesized to be involved in the metabolic adaptations induced by $\mathrm{CHO}$ restriction in the treatment of obesity. The results indicate that the magnitude of weight loss induced by a $\mathrm{CHO}$ restricted diet is, in part, explained by polymorphisms in specific genes among those we selected to study: genes that regulate lipases, intracellular glucose metabolism, HDL homeostasis, and appetite hormones.

\section{Methods}

\section{Subjects and study design}

The subjects included 86 adults who participated in very low $\mathrm{CHO}$ dietary studies designed to examine the effects on weight loss, body composition, and other metabolic responses related to cardiovascular disease in the Human Performance Laboratory at the University of Connecticut (Table 1). The subjects included 10 normal weight women studied over 4 weeks [21], 15 overweight men and 13 overweight women studied over 4-6 wk [20], 28 overweight men studied over $12 \mathrm{wk}$ [22], and 10 overweight men and 10 overweight women with metabolic syndrome studied over $12 \mathrm{wk}$ (unpublished). Subjects did not have diabetes, cardiovascular, respiratory, gastrointestinal, thyroid or any other metabolic disease. They were weight stable $( \pm 2 \mathrm{~kg}$ ) the month prior to starting the study, and were not allowed to use nutritional supplements (except a daily multi-vitamin/mineral), or be taking medications to control blood lipids or glucose. The majority of subjects were sedentary and all participants were instructed to maintain the same level of physical activity throughout the study. Before and after the low CHO diet, body mass was determined in the morning after an overnight fast on a calibrated digital scale with subjects in light clothing and not wearing shoes. All subjects signed an informed consent document approved by the Institutional Review Board.

\section{Dietary protocol}

The diet intervention was free-living with the main goal to restrict $\mathrm{CHO}$ to a level that induced a small level of ketosis. There were no restrictions on the type of fat from saturated and unsaturated sources or cholesterol levels. Foods commonly consumed were beef (e.g., hamburger, steak), poultry (e.g., chicken, turkey), fish, vegetable oils, various nuts/seeds and peanut butter, moderate amounts of vegetables, salads with low $\mathrm{CHO}$ dressing, moderate amounts of cheese, eggs, protein drinks, and water or low $\mathrm{CHO}$ diet drinks. The use of sugar alcohol-containing low $\mathrm{CHO}$ foods was permitted but limited to one item per day. To ensure appropriate $\mathrm{CHO}$ restriction, subjects monitored their level of ketosis daily using urine reagent strips that produce a relative color change in the presence of one of the primary ketones, acetoacetic acid. We have found this to be a very sensitive indicator of $\mathrm{CHO}$ restriction and compliance. Blood ketones were also checked during the diets. On this basis, all subjects in our low $\mathrm{CHO}$ studies were in ketosis for the majority of the experimental period. All subjects received extensive initial verbal and written instructions and weekly follow-up dietetic education. Subjects received thorough instructions for completing detailed weighed food records during baseline 
Table I: Mean body mass and weight loss broken down by gender, age, ethnicity, and length of diet.

\begin{tabular}{|c|c|c|c|c|c|}
\hline Factor & Level & $\mathbf{N}$ & Pre Body Mass (kg) & Change Body Mass (kg) & Genotyped \\
\hline All & All & 86 & 89.4 & -6.42 & 72 \\
\hline Gender & Female & 33 & 74.7 & -4.33 & 32 \\
\hline Gender & Male & 53 & 98.5 & -7.73 & 40 \\
\hline Age & $<40 \mathrm{yr}$ & 56 & 88.8 & -6.12 & 48 \\
\hline Age & $40-49 \mathrm{yr}$ & 21 & 89.8 & -6.08 & 16 \\
\hline Age & $50-59 \mathrm{yr}$ & 6 & 94.7 & -8.87 & 5 \\
\hline Age & $60-69 \mathrm{yr}$ & 3 & 86.2 & -9.70 & 3 \\
\hline Ethnicity & African Am & 5 & 83.4 & -5.60 & 3 \\
\hline Ethnicity & Asian & I & 60.9 & -2.30 & 1 \\
\hline Ethnicity & Caucasian & 74 & 90.8 & -6.52 & 63 \\
\hline Ethnicity & Hispanic & 3 & 78.6 & -6.10 & 3 \\
\hline Ethnicity & Indian & 3 & 84.3 & -7.13 & 2 \\
\hline Length & 4 & 23 & 68.2 & -2.20 & 23 \\
\hline Length & 6 & 15 & 106.8 & -6.27 & 11 \\
\hline Length & 12 & 48 & 94.1 & -8.50 & 38 \\
\hline
\end{tabular}

and various phases of the diet that were subsequently analyzed using regularly updated nutrient analysis software. The actual mean nutrient breakdown of the diets as a percentage of total energy as obtained from at least 15 days of weighed food records from four cohorts of subjects was 8$13 \% \mathrm{CHO}, 60-63 \%$ fat, and $28-30 \%$ protein (see Supplemental File).

\section{Candidate gene selection}

Eleven candidate genes were broadly selected for their various roles in regulation of body weight. We chose representative genes coding for products from four pathways and processes that we hypothesized as playing an important role in mediating weight loss induced by $\mathrm{CHO}$ restriction including (1) enzymes regulating digestion, trafficking, and intracellular metabolism of fat, (2) enzymes regulating intracellular glucose metabolism, (3) proteins affecting lipoprotein remodeling and metabolism, and (4) hormones regulating appetite (Table 2).

\section{Laboratory analysis}

Blood samples were collected from an arm vein into tubes for DNA extraction. The DNA was extracted from $8.5 \mathrm{~mL}$ of whole blood using the PreAnalytiX PAXgene DNA isolation kit (Qiagen Inc, Valencia, CA). For some earlier participants, neither whole blood nor DNA were available, so DNA from lymphocytes remaining in archived serum samples were amplified using the QiaGen REPLI-g Whole Genome Amplification kit. Genotyping was performed using the Illumina BeadArray ${ }^{\mathrm{TM}}$ platform and the GoldenGate $^{\mathrm{TM}}$ assay $[23,24]$. The assay information and observed allele frequencies for the SNPs used in this study are listed in Table 2. Genotype calls of sufficient quality could not be obtained for 14 subjects, which were left in the study to contribute to the covariate model, but did not contribute directly to the genetic associations.

\section{Data analysis}

All statistical analysis was performed using the R Statistics Language and Environment [25-27]. Covariates were analyzed using multiple linear regression, and selected using the stepwise procedure. To test for association with SNP genotypes, the residual of $\Delta$ body mass from the covariate model was tested using linear regression on the SNP genotypes. SNP genotype was coded quantitatively as a numerical variable indicating the number of minor alleles: 0 for major homozygotes, 1 for heterozygotes, and 2 for minor homozygotes. The F-statistic p-value for the SNP variable was used to evaluate the significance of association. To test the validity of the p-values, we also performed an independent calculation of the p-values using permutation testing. The ranking of the first three SNPs were identical under permutation and F-statistic analyses (data not shown). To account for the multiple testing of 27 SNPs, we calculated adjusted p-values using Benjamini and Hochbergs false discovery rate (FDR) procedure [2830]. In addition, we evaluated the power for detecting an association based on the Bonferroni multiple comparison adjustment. We calculated for each SNP the effect size in standard deviations that is necessary for detection of an association at a power of $80 \%$ (20\% false negative rate) using the formula

$\Delta=\frac{z_{\alpha / c}+z_{\beta}}{\sqrt{N f(1-f)}}$,

where $\mathrm{a}$ is the desired false positive rate $(\mathrm{a}=0.05), \mathrm{b}$ the false negative rate $(b=1$-Power $=0.2)$, $c$ the number of SNPs, $\mathrm{z}$ a standard normal deviate, $\mathrm{N}$ the number of subjects, $\mathrm{f}$ the carrier proportion, and $\Delta$ the difference in $\Delta$ body mass between carriers and non-carriers expressed relative to the standard deviation [31]. 
Table 2: List of 15 genes and 27 SNPs studied for association with weight loss induced by a low CHO diet.

\begin{tabular}{|c|c|c|c|c|c|c|c|c|c|c|}
\hline $\begin{array}{c}\text { Gene } \\
\text { Family or } \\
\text { Pathway }\end{array}$ & Gene & SNP & $\mathbf{N}$ & mac & $\min$ & maj & Freq & Gene & Description & Sequence Context \\
\hline \multirow[t]{10}{*}{ Lipases } & Hepatic lipase & rs936960 & 49 & 7 & A & C & 0.07 & LIPC & lipase, hepatic & $\begin{array}{l}\text { CAGAGCACGAGGCTGATTTTC [A] } \\
\text { C]ATCCCAGTGTGGGCCACACC }\end{array}$ \\
\hline & & rs4I 7344 & 50 & 13 & $\mathrm{~T}$ & $\mathrm{C}$ & 0.13 & LIPC & lipase, hepatic & $\begin{array}{l}\text { TTTCCTAATTTTGCAGTTGAG [A/ } \\
\text { G]TTTAAGAGGTTGGGAACTGG }\end{array}$ \\
\hline & & rs 6083 & 39 & 28 & A & G & 0.36 & LIPC & lipase, hepatic & $\begin{array}{l}\text { GTCTTTCTCCAGATGATGCCA [A/ } \\
\text { G]TTTTGTGGATGCCATTCATA }\end{array}$ \\
\hline & Lipoprotein lipase & rs295 & 46 & 15 & $A$ & C & 0.16 & LPL & lipoprotein lipase & $\begin{array}{l}\text { GATGCACCTACTAGACACCTA [A/ } \\
\text { C]TCTGCGCTAGATGGTGGGGG }\end{array}$ \\
\hline & & rs328 & 53 & 10 & C & G & 0.09 & LPL & lipoprotein lipase & $\begin{array}{l}\text { ACAAGTCTCTGAATAAGAAGT [C/ } \\
\text { G]AGGCTGGTGAGCATTCTGGG }\end{array}$ \\
\hline & $\begin{array}{l}\text { Hormone sensitive } \\
\text { lipase }\end{array}$ & rs 10422283 & 43 & 26 & $\mathrm{~T}$ & C & 0.30 & LIPE & lipase, hormone-sensitive & $\begin{array}{l}\text { GGAAGGAACCTCGTACATCCT [A/ } \\
\text { G]CGGGGCAGTGGGGACAGCGT }\end{array}$ \\
\hline & Lysosomal acid lipase & rsI556478 & 35 & 28 & $A$ & G & 0.40 & LIPA & $\begin{array}{l}\text { lipase A, lysosomal acid, } \\
\text { cholesterol esterase } \\
\text { (Wolman disease) }\end{array}$ & $\begin{array}{l}\text { CACGGAGACTTATGCACCAGA [A/ } \\
\text { G]TGAAATGCTGAGATGTTCTT }\end{array}$ \\
\hline & & rs6586179 & 45 & 7 & $\mathrm{~T}$ & C & 0.08 & LIPA & $\begin{array}{l}\text { lipase } A \text {, lysosomal acid, } \\
\text { cholesterol esterase } \\
\text { (Wolman disease) }\end{array}$ & $\begin{array}{c}\text { ACCCTGCATTCTGAGGGGTCT [A/ } \\
\text { G]GAGGGAAACTGACAGCTGTG }\end{array}$ \\
\hline & Endothelial lipase & rs4245232 & 45 & 15 & A & C & 0.17 & LIPG & lipase, endothelial & $\begin{array}{l}\text { TAAAAAACTAAAGCCCGCCTG [A/ } \\
\text { C]GTCTTGTTAATGAATGATAG }\end{array}$ \\
\hline & Gastric lipase & rs814628 & 45 & 9 & $A$ & G & 0.10 & LIPF & lipase, gastric & $\begin{array}{l}\text { ATCGACTTCATTGTAAAGAAA [A/ } \\
\text { G]CTGGACAGAAGCAGCTACAC }\end{array}$ \\
\hline \multirow[t]{6}{*}{$\begin{array}{l}\text { Glycogen } \\
\text { Synthases }\end{array}$} & $\begin{array}{l}\text { Glycogen Synthase I } \\
\text { (muscle) }\end{array}$ & rs2287754 & 35 & 16 & A & G & 0.23 & GYSI & $\begin{array}{l}\text { glycogen synthase I } \\
\text { (muscle) }\end{array}$ & $\begin{array}{l}\text { CGGGAAGCTTGCAAGACGCTC [A] } \\
\text { G]GCTTCCTATTGCAAGACCGC }\end{array}$ \\
\hline & $\begin{array}{l}\text { Glycogen Synthase } 2 \\
\text { (hepatic) }\end{array}$ & rs|478290 & 59 & 29 & $\mathrm{~T}$ & G & 0.25 & GYS2 & glycogen synthase 2 (liver) & $\begin{array}{l}\text { AATGTGGCTGAAGCCAAAAGC [A/ } \\
\text { C]TAATGAATGAGGGGAAGCCT }\end{array}$ \\
\hline & & rs|87||43 & 40 & 23 & $\mathrm{~T}$ & G & 0.29 & GYS2 & glycogen synthase 2 (liver) & $\begin{array}{l}\text { AGCCAGGAGCTTTCCTGGGCG [A/ } \\
\text { C]TTTTTGTACAGGATCTCATT }\end{array}$ \\
\hline & & rs2306179 & 44 & 18 & A & G & 0.20 & GYS2 & glycogen synthase 2 (liver) & $\begin{array}{l}\text { TTTCAGTAGGTTTGCAGGGAA [A/ } \\
\text { G]CCAACTCAAAGCTATATCTG }\end{array}$ \\
\hline & Glycogen Synthase 3b & rs4688046 & 44 & 19 & $\mathrm{~T}$ & C & 0.22 & GSK3B & $\begin{array}{l}\text { glycogen synthase kinase } 3 \\
\text { beta }\end{array}$ & $\begin{array}{l}\text { TAGTAAACTATTTCTTCCCAT [A/ } \\
\text { G]GGAGAAGATGGATTCTTTTC }\end{array}$ \\
\hline & & rs334555 & 43 & 7 & C & G & 0.08 & GSK3B & $\begin{array}{l}\text { glycogen synthase kinase } 3 \\
\text { beta }\end{array}$ & $\begin{array}{l}\text { AATTATATCTTATTATTAAAA [C/ } \\
\text { G]TCTACCAACTCAAAGCTTCC }\end{array}$ \\
\hline \multirow[t]{8}{*}{$\begin{array}{l}\text { HDL } \\
\text { Homeostasis }\end{array}$} & CETP & rs711752 & 46 & 36 & A & G & 0.39 & CETP & $\begin{array}{l}\text { cholesteryl ester transfer } \\
\text { protein, plasma }\end{array}$ & $\begin{array}{l}\text { TTCAAGGTCAAGTTCTTTGGT [A/ } \\
\text { G]AGAAGGTCCTAGCTGCATTG }\end{array}$ \\
\hline & & rs376426I & 41 & 20 & $\mathrm{~T}$ & G & 0.24 & CETP & $\begin{array}{l}\text { cholesteryl ester transfer } \\
\text { protein, plasma }\end{array}$ & $\begin{array}{l}\text { AGTGAATGAGATAGCAGACAA [A/ } \\
\text { C]CCAGATGCCTACCGACAGGT }\end{array}$ \\
\hline & & rs5880 & 44 & 4 & C & G & 0.05 & CETP & $\begin{array}{l}\text { cholesteryl ester transfer } \\
\text { protein, plasma }\end{array}$ & $\begin{array}{l}\text { GATATCGTGACTACCGTCCAG [C/ } \\
\text { G]CCTCCTATTCTAAGAAAAGC }\end{array}$ \\
\hline & & rsI532624 & 51 & 33 & $\mathrm{~T}$ & G & 0.32 & CETP & $\begin{array}{l}\text { cholesteryl ester transfer } \\
\text { protein, plasma }\end{array}$ & $\begin{array}{l}\text { TCTGCCCCTTTGGGCTGCAGC [A/ } \\
\text { C]TCACAAGCTGTGTGGCGTTG }\end{array}$ \\
\hline & & rs5883 & 56 & 8 & $\mathrm{~T}$ & C & 0.07 & CETP & $\begin{array}{l}\text { cholesteryl ester transfer } \\
\text { protein, plasma }\end{array}$ & $\begin{array}{l}\text { AGCTACCTTGGCCAGCGAGTG [A/ } \\
\text { G]AAGACTCGCTCAGAGAACCA }\end{array}$ \\
\hline & APOAI & rs5070 & 41 & 18 & A & G & 0.22 & $\begin{array}{c}\text { APOA } \\
1\end{array}$ & apolipoprotein A-I & $\begin{array}{l}\text { GCCACGGGGATTTAGGGAGAA [A/ } \\
\text { G]GCCCCCCGATGGTTGGCTCC }\end{array}$ \\
\hline & APOC3 & rs 4520 & 38 & 23 & $\mathrm{~T}$ & C & 0.30 & $\begin{array}{c}\mathrm{APOC} \\
3\end{array}$ & apolipoprotein C-III & $\begin{array}{l}\text { CTTGGTGGCGTGCTTCATGTA [A/ } \\
\text { G]CCCTGCATGAAGCTGAGAAG }\end{array}$ \\
\hline & & rs207|52I & 45 & 37 & $\mathrm{~T}$ & C & 0.41 & $\begin{array}{c}\mathrm{APOC} \\
3\end{array}$ & apolipoprotein C-III & $\begin{array}{l}\text { ACAGCTCCTGTTGCCATAGGA [A/ } \\
\text { G]GGAGCTGGGTGAGATACTAG }\end{array}$ \\
\hline \multirow[t]{3}{*}{$\begin{array}{l}\text { Appetite } \\
\text { Hormones }\end{array}$} & Galanin & rs694066 & 56 & 6 & A & G & 0.05 & GAL & galanin & $\begin{array}{l}\text { TTCTAAGTCCTCTGCCATGCC [A/ } \\
\text { G]GGAAAGCCTGGGTGCACCCA }\end{array}$ \\
\hline & Neuro-peptide $Y$ & rs |46827| & 48 & 5 & A & G & 0.05 & NPY & neuropeptide $Y$ & $\begin{array}{l}\text { GACCCTGTAATTTTCAGAAAC [A/ } \\
\text { G]CACATAGGAGTGGGTGTCTG }\end{array}$ \\
\hline & Ghrelin Precursor & rs 26312 & 63 & 14 & A & G & 0.11 & GHRL & ghrelin precursor & $\begin{array}{c}\text { GCTGTTGCTGCTCTGGCCTCT [A] } \\
\text { G]TGAGCCCCGGGAGTCCGCAG }\end{array}$ \\
\hline
\end{tabular}

SNP identification numbers (noted as "rs...") are the unique SNP identifiers from the NCBI dbSNP database. Also given are the number of patients with good genotype results $(\mathrm{N})$, the number of minor alleles found (mac), and the corresponding allele frequency as observed in this study.

\section{LOESS representation}

We use a locally smoothed function of the SNP frequency as it varies with body mass to visually represent the nature of an association. LOESS (LOcally wEighted Scatter plot Smooth) is a method to smooth data using a locally weighted linear regression [32,33]. At each point in the LOESS curve, a quadratic polynomial is fitted to the data in the vicinity of that point. The data are weighted such that they contribute less if they are further away, according to the tricubic function

$$
w_{i}=\left(1-\left|\frac{x-x_{i}}{d(x)}\right|^{3}\right)^{3}
$$


Table 3: Potential covariates examined. The 3 statistically significant ones are shown in italics with corresponding significance level, p value.

\begin{tabular}{lll}
\hline Name & Measure & Description \\
\hline Gender & male, female & Patient gender \\
Age & integer & Patient age \\
Ethnicity & African American, Asian, Caucasian, Hispanic, Indian & Patient self reported ethnicity \\
Length & 4,6, or $12 \mathrm{wk}$ & Length of diet \\
$T C$ & $\mathrm{mg} / \mathrm{dl}$ & Total cholesterol \\
$\mathrm{LDL}$ & $\mathrm{mg} / \mathrm{dl}$ & LDL cholesterol \\
$\mathrm{HDL}$ & $\mathrm{mg} / \mathrm{dl}$ & HDL cholesterol \\
TG & $\mathrm{mg} / \mathrm{dl}$ & Tryglycerides \\
THDLR & $\mathrm{ratio}$ & Ratio of Total to HDL-C \\
BMS & $\mathrm{kg}$ & Body mass \\
$\mathrm{FM}$ & $\mathrm{kg}$ & Fat mass \\
LBM & $\mathrm{kg}$ & Lean body mass \\
PF & $\mathrm{percent}$ & Percent body fat \\
BMI & $\mathrm{kg} / \mathrm{m} 2$ & Body mass index \\
\end{tabular}

where $x$ is the abscissa of the point to be estimated, the $x_{i}$ are the data points in the vicinity, and $d(x)$ is the maximum distance of $x$ to the $x_{i}$.

\section{Results}

Table 1 summarizes the weight loss data available for the study population. The distribution of weight loss was non-gaussian (Figure 1). Of the potential covariates listed in Table 3, length of diet, body mass index, and baseline total cholesterol were significantly associated with weight loss. Length of diet, in particular, accounted for an increased weight loss of $0.55 \mathrm{~kg}$ with each additional week of diet. Increased baseline body mass index (BMI) was also correlated with weight loss. There was a relationship between total cholesterol level and weight loss, with an additional 19 grams of weight lost for every $\mathrm{mg} / \mathrm{dl}$ of total cholesterol at the beginning of the study.

After adjusting for the associations in Table 3, each SNP in Table 2 was tested for association with the residual variable (body mass adjusted for the covariates) (Table 4). Of the 27 SNPs, four had a statistically significant association with the residual body mass, namely gastric lipase (LIPF, SNP rs814628), cholesteryl ester transfer protein (CETP, SNP rs5883), hepatic glycogen synthase 2 (GYS2, SNP rs2306179), and galanin (GAL, SNP rs694066). The first three results remained significant when adjustment was made for the testing of multiple SNPs using the FDR method.

Figures 2, 3, 4, 5 show a detailed representation of the genetic association tests for all genes. The overall distribution of change in body mass is shown along with the individual genotypes and a LOESS fit of the allele frequency as a function of body mass. The bell curve shows the fitted distribution of body mass phenotype in the clinical stud- ies. The LOESS curve shows the localized frequency of the least common allele for sectors of the distribution. For SNPs with a strong association, the marker frequency will be significantly different between the high end and the low end of the distribution. Conversely, if a marker is neutral, the frequency will be independent on the body mass and the LOESS curve will be essentially flat.

For example, the first panel in Figure 2 shows the LOESS curve for SNP rs814628, which is located in the gene for gastric lipase (LIPF). The frequency of the minor allele approaches $60 \%$ at the highest amount of weight loss (left of the distribution) whereas it is $5 \%$ in subjects with little body mass change (right of the distribution). The overall frequency of this SNP in the study population is $10 \%$ (Table 2). This marked dependence of SNP frequency with the phenotype is indicative of a strong association between the gene marker and body mass, as attested by a $\mathrm{p}$ value of 0.0002 (Table 4).

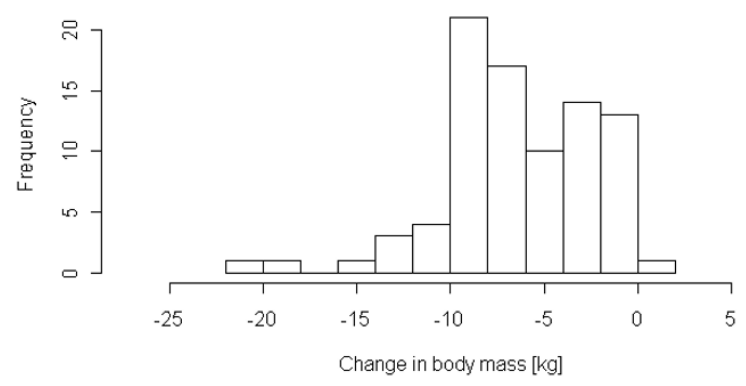

Figure I

Distribution of change in body mass (weight loss) in the study population. 
Table 4: Results of the association test of each SNP against the phenotypic variation residual from the regression of covariates in Table 3. Results significant at alpha $\leq \mathbf{0 . 0 5}$ are indicated in bold. Also shown are the FDR corrected p-value, the degrees of freedom in the regression model, the regression coefficient indicating the size of the effect of the minor allele, and the minimum effect size for $80 \%$ power of detection, relative to the standard deviation.

\begin{tabular}{|c|c|c|c|c|c|c|c|}
\hline SNP & Gene & p-value & FDR & degf & coeff & power & SNP type \\
\hline rs936960 & LIPC & 0.7354 & 0.8011 & 47 & 0.351 & 2.08 & intron I \\
\hline rs4I7344 & LIPC & 0.1322 & 0.5433 & 48 & 1.175 & 1.57 & $\sim 5.5 \mathrm{~kb}$ upstream from LIPC \\
\hline rs6083 & LIPC & 0.6944 & 0.8011 & 37 & -0.226 & 1.25 & S2I5N \\
\hline rs295 & LPL & 0.5519 & 0.7843 & 44 & -0.526 & 1.49 & intron 6 \\
\hline rs328 & LPL & 0.1973 & 0.5744 & 51 & -1.330 & 1.76 & exon $9, * 474 S$ \\
\hline rs 10422283 & LIPE & 0.1610 & 0.5433 & 41 & 0.916 & 1.24 & intron I \\
\hline rs I556478 & LIPA & 0.7417 & 0.8011 & 33 & 0.228 & 1.29 & intron 5 \\
\hline rs6586179 & LIPA & 0.2575 & 0.6321 & 43 & -1.189 & 2.08 & exon I, R23G \\
\hline rs 4245232 & LIPG & 0.1561 & 0.5433 & 43 & 0.906 & 1.50 & $\sim 1.5 \mathrm{~kb}$ upstream \\
\hline rs8 I 4628 & LIPF & 0.0002 & 0.0059 & 43 & -3.658 & 1.86 & exon 4 , Ala | 6 I $>$ Thr \\
\hline rs2287754 & GYSI & 0.6950 & 0.8011 & 33 & -0.324 & 1.51 & 5' UTR \\
\hline rs 1478290 & GYS2 & 0.4504 & 0.7843 & 57 & -0.381 & 1.13 & $\sim 3.5 \mathrm{~Kb}$ upstream \\
\hline rs 1871143 & GYS2 & 0.5236 & 0.7843 & 38 & -0.381 & 1.31 & intron II \\
\hline rs2306179 & GYS2 & 0.0068 & 0.0610 & 42 & -1.717 & 1.40 & intron 5 \\
\hline rs4688046 & GSK3B & 0.5148 & 0.7843 & 42 & -0.382 & 1.37 & intron 3 \\
\hline rs334555 & GSK3B & 0.4553 & 0.7843 & 41 & 0.925 & 2.09 & intron I \\
\hline rs7।I752 & CETP & 0.2127 & 0.5744 & 44 & 0.677 & 1.13 & intron I \\
\hline rs376426I & CETP & 0.6900 & 0.8011 & 39 & 0.263 & 1.36 & $\sim 2.6 \mathrm{~kb}$ upstream \\
\hline rs5880 & CETP & 0.0782 & 0.4220 & 42 & 2.769 & 2.71 & P390A \\
\hline rs 1532624 & CETP & 0.5299 & 0.7843 & 49 & 0.339 & 1.12 & intron 7 \\
\hline rs5883 & CETP & 0.0018 & 0.0237 & 54 & -2.854 & 1.94 & exon 9 , synonymous \\
\hline rs5070 & APOAI & 0.4406 & 0.7843 & 39 & -0.454 & 1.41 & Intron \\
\hline rs 4520 & APOC3 & 0.4275 & 0.7843 & 36 & -0.497 & 1.32 & G34G \\
\hline rs207I52I & APOC3 & 0.9176 & 0.9176 & 43 & -0.053 & 1.13 & Upstream \\
\hline rs694066 & GAL & 0.0231 & 0.1557 & 54 & 2.105 & 2.22 & intron I \\
\hline rs|46827I & NPY & 0.7401 & 0.8011 & 46 & -0.378 & 2.43 & intron I \\
\hline rs26312 & GHRL & 0.7832 & 0.8133 & 61 & 0.233 & 1.50 & $\sim$ l kb upstream \\
\hline
\end{tabular}

\section{Discussion}

The principal metabolic adaptations contributing to weight loss induced by $\mathrm{CHO}$ restriction are unknown. This study used physiogenomic analysis to examine the relations between genes regulating target proteins impacting the intake and metabolism of dietary nutrients and weight loss in subjects on a very low $\mathrm{CHO}$ diet. The change with length of diet is a good confirmation that it is indeed the low $\mathrm{CHO}$ intervention that caused the weight loss, although it is unknown if similar changes would be found if weight loss were brought about by other types of diets. Genetic polymorphisms also significantly associate with weight loss when these factors are used as a covariate indicating that genetic variation may be a valuable tool to predict individual variability in weight loss to dietary $\mathrm{CHO}$ restriction. The results indicate that common genetic markers in gastric lipase, glycogen synthase, CETP, and galanin have a substantial effect on weight loss response to $\mathrm{CHO}$ restricted diets.

Very low $\mathrm{CHO}$ diets are typically higher in fat. We therefore hypothesized that polymorphisms in various lipases may account for variability in weight loss. We tested SNPs in genes for gastric, hepatic, lipoprotein, hormone-sensi- tive, lysosomal acid, and endothelial lipase. Unexpectedly, we discovered the gastric isoenzyme was the most significant genetic association to weight loss, whereas other lipases were not. Gastric lipase is secreted by the mucosa of the stomach and hydrolyzes the ester bonds of dietary triglycerides in the gastrointestinal tract. Pancreatic lipase is generally the dominant enzyme in the hydrolysis of gastrointestinal lipids, but gastric lipase can contribute significantly especially in instances where pancreatic lipase is deficient [34]. Thus a significant locus of variability is the ability to perform first pass breakdown of dietary fat. Individuals with the least common version of the enzyme had the most weight loss, indicating that impairment of gastric fat breakdown on a low $\mathrm{CHO}$ diet enhances weight loss.

The second category of genes we surveyed was related to glycogen synthesis. Glycogen synthase catalyzes the formation of glycogen from glucose. A defect in this pathway in skeletal muscle has a dominant role in the insulin resistance that occurs in diabetes [35]. Polymorphisms in glycogen synthase kinase beta (GSK3B), a regulator of glycogen synthase activity, and skeletal muscle glycogen synthase 1 (GYS1) have been examined in several studies, but 

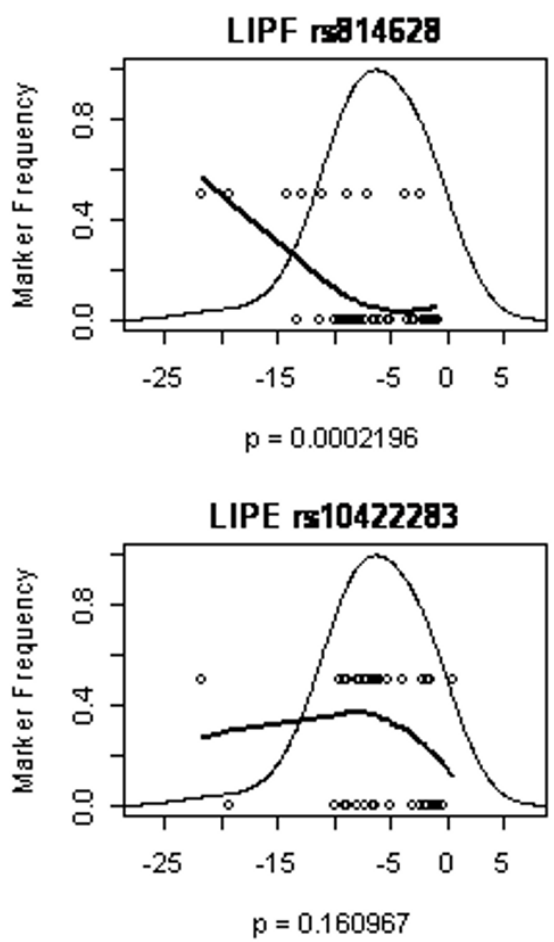

LIPC FA17344

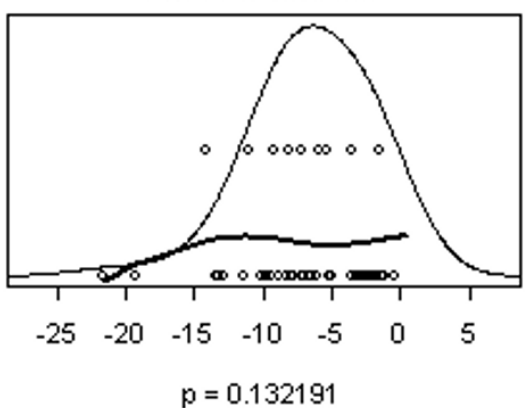

LPL rs:328

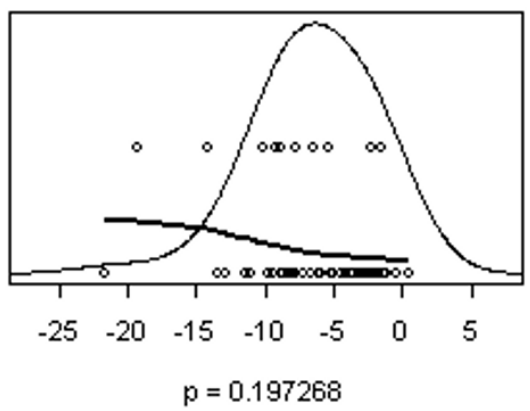

LIPG Is4245232

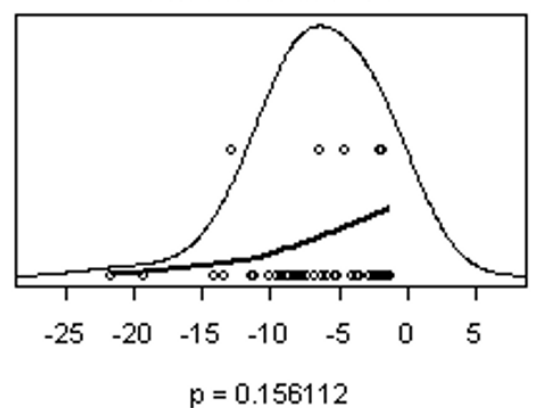

LIPA r 55586179

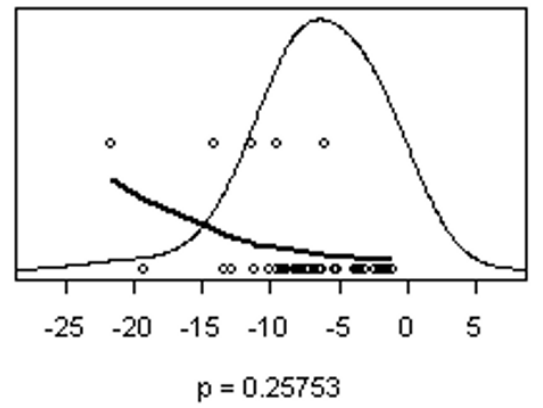

Figure 2

LOESS plots for six lipase genes listed in order of genetic association significance, as follows: LIPF gastric lipase, LIPC hepatic lipase, LIPG endothelial lipase, LIPE hormone-sensitive lipase, LPL lipoprotein lipase, LIPA lipase A lysosomal acid. One SNP is shown per gene, with corresponding significance level ( $p$ value), from Table 4. SNP rs8I4628 of the gastric lipase (LIPF) gene was significantly associated with weight loss while the others were not. The $\mathbf{x}$-axis is the same as in figure I: change in body mass $[\mathrm{kg}]$.

have generally failed to associate with diabetes or measures of insulin resistance [36,37]. In addition to GSK3B and GYS1, we examined hepatic glycogen synthase 2 because recent work also indicates that insulin stimulated hepatic glycogen synthesis is impaired in diabetics [38]. We discovered that a polymorphism in hepatic, but not skeletal muscle, glycogen synthase was associated with weight loss. The results suggest that the hepatic response to carbohydrate restriction may influence the weight loss response to a low $\mathrm{CHO}$ diet.

In addition to weight loss, our prior work has shown that low $\mathrm{CHO}$ diets result in reliable and dramatic changes in lipoprotein metabolism characterized by decreased triglycerides and remodeling of LDL and HDL cholesterol to form larger particles $[1,22]$. Since weight loss has similar effects, we surveyed various apolipoproteins and enzymes regulating triglyceride and lipoprotein metabolism including CETP, apolipoprotein A-I, and apolipoprotein C-III. We found that a specific polymorphism in plasma CETP was significantly associated with weight loss. The major function of CETP is the net mass transfer of cholesterol esters from HDL to triglyceride-rich lipoproteins and
LDL-C and of triglyceride-rich lipoproteins to HDL-C and LDL-C [39], thereby providing a mechanistic link to explain the triglyceride lowering and remodeling effects of LDL and HDL observed with low CHO diets [22,40]. Several studies have linked polymorphisms in the CETP gene to lipoprotein responses and risk for cardiovascular disease, and it has been hypothesized that these relations may be altered by weight loss [41]. Our study is the first study to show an association of a polymorphism in CETP gene to weight loss. The finding suggests that the weight loss response to $\mathrm{CHO}$ restriction may be mechanistically linked to the intravascular processing of lipoproteins.

Hormonal regulation of food intake was hypothesized to be one mechanism by which $\mathrm{CHO}$ restricted diets affect weight loss. We examined polymorphisms in galanin, neuropeptide $\mathrm{Y}$, and ghrelin. Galanin was the only hormone significantly associated with weight loss. Galanin stimulates food consumption, particularly fat intake. A prior study that measured polymorphisms in galanin failed to find an association with fat intake or obesity [42]. Prior work has shown that galanin in the para-ventricular nucleus is stimulated by a fat feeding and increased circu- 

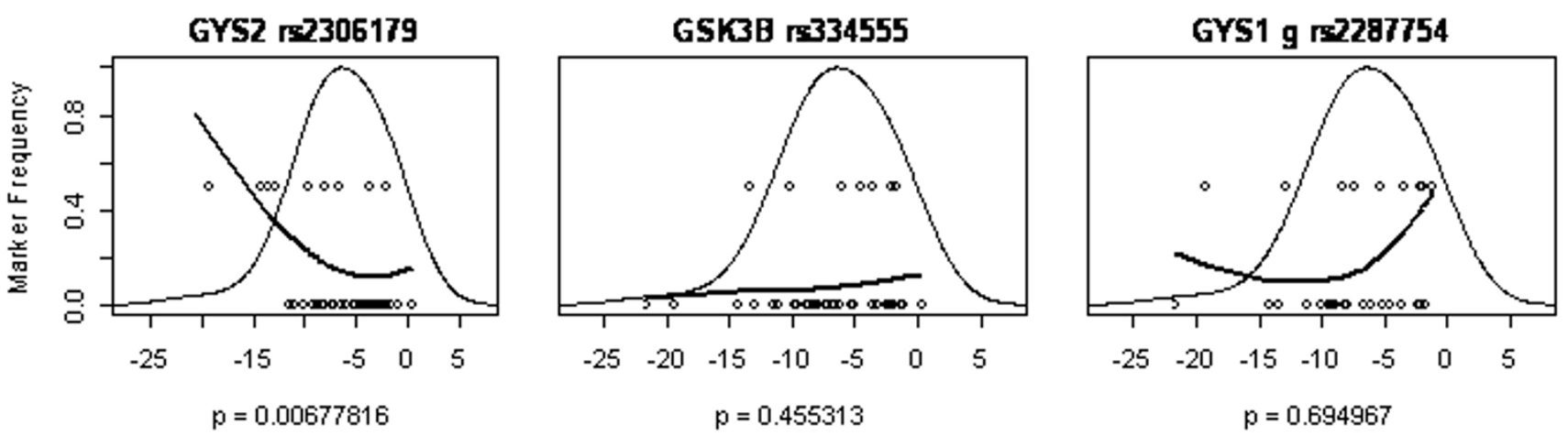

Figure 3

LOESS plots for 3 glycogen synthase genes listed in order of genetic association significance, as follows: GYS2 glycogen synthase 2 (liver), GSK3B glycogen synthase kinase 3 beta, GYSI glycogen synthase I (muscle). One SNP is shown per gene, with corresponding significance level ( $p$ value), from Table 4. SNP rs2306I 79 of the GYS2 gene was significantly associated with weight loss while the others were not. The $\mathrm{x}$-axis is the same as in figure I: change in body mass [kg].

lating triglycerides, which in turn promotes further fat consumption in a non-homeostatic feed-forward manner [43]. The finding in this study that a polymorphism surveyed in the galanin gene was associated with weight loss provides evidence for a role of fat-mediated appetite hormones in determining the response to carbohydrate restriction.

Physiogenomics introduces a new paradigm in the genetic analysis of complex phenotypes. Historically, a candidate gene approach identified one specific hypothesis. However, such focused hypotheses are often unrealistic given the number of overlapping pathways at the organismic, cellular, and molecular levels. Array technologies provide efficient methods to simultaneously probe large numbers of genes using general hypotheses about entire pathways and systems. As a previous example of this approach, we had demonstrated a strong association between CK activity during statin treatment and variability in genes related to vascular function, angiotensin II Type 1 receptor (AGTR1) and nitric oxide synthase 3 (NOS3) [44]. This finding had led us to suggest the novel hypothesis that vascular smooth muscle function may contribute to the muscle side effects of statins.

Similarly, we believe that novel hypotheses have been generated in this study. The approach to select gene families or functionally related genes generates positive and negative results for physiogenomic analysis. It is the contrast in statistical significance levels within each of the
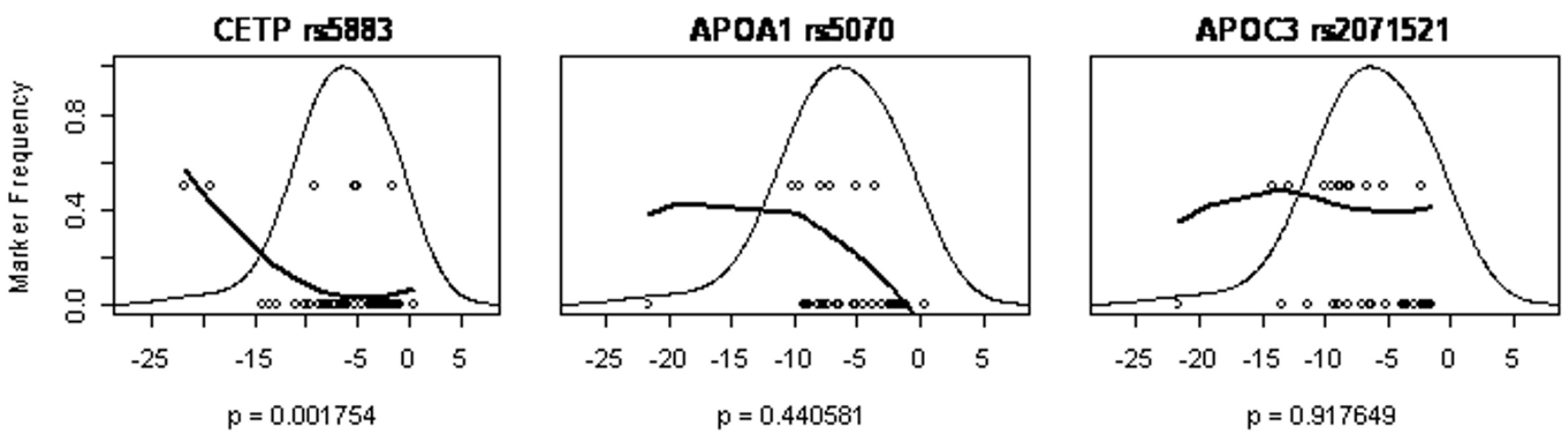

\section{Figure 4}

LOESS plots for the lipid metabolism listed in order of genetic association significance, as follows: CETP, cholesteryl ester transfer protein, plasma, APOAI apolipoprotein A-I, APOC3 apolipoprotein C-III. One SNP is shown per gene, with corresponding significance level ( $p$ value), from Table 4. SNP rs5883 of the CETP gene was significantly associated with weight loss while the others were not. The $\mathrm{x}$-axis is the same as in figure I: change in body mass [kg]. 

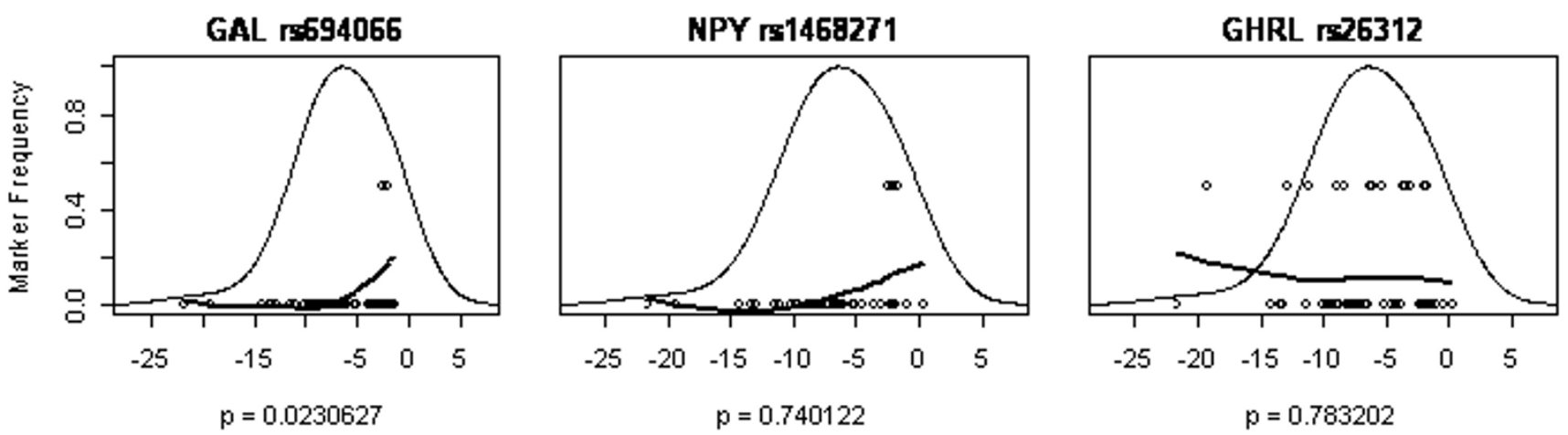

Figure 5

LOESS plots for the appetite regulation hormone listed in order of genetic association significance, as follows: GAL galanin, NPY neuropeptide Y, GHRL ghrelin precursor. One SNP is shown per gene, with corresponding significance level ( $P$ value), from Table 4. SNP rs694066 of the GAL gene was significantly associated with weight loss while the others were not.

four functional groups pursued in this study that provides the mechanistic insight. The associated gene markers can be combined into SNP ensembles harnessing their combined predictive power to estimate weight loss attainable from carbohydrate restriction for each individual. The SNP ensemble can then be tested retrospectively or prospectively to assess its predictive diagnostic power in populations separate from the ones used to generate the model. We believe this approach is pivotal to the discovery of multi-gene effects determining human dietary response. Applications to the management of obesity and diabetes include individualized counseling and dietary choice based on innate capacity to react to various nutritional regimens. We foresee the translation of these findings to diagnostic systems for personalized diet.

\section{Competing interests}

Dr. Ruano, Mr. Kocherla and Dr. Windemuth are full-time employees and shareholders of Genomas Inc.

\section{Authors' contributions}

JSV, MLF, WJK were involved with the acquisition of funding, design, conception and execution of the dietary intervention and biochemical analysis portion of the study, as well as acquisition, analysis and interpretation of data. CEF and RJW were primarily involved in data acquisition, analysis and interpretation of data. GR, AW, and MK performed the genetic analysis. GR, TH, and AW performed the statistical analysis. All authors were involved in the drafting and revision of the manuscript and give their final approval of this version to be published.

\section{References}

I. Volek JS, Feinman RD: Carbohydrate restriction improves the features of Metabolic Syndrome. Metabolic Syndrome may be defined by the response to carbohydrate restriction. Nutr Metab (Lond) 2005, 2:3I.
2. Westman EC, Mavropoulos J, Yancy WS, Volek JS: A review of lowcarbohydrate ketogenic diets. Curr Atheroscler Rep 2003, 5(6):476-483.

3. Feinman RD, Fine Ej: Thermodynamics and metabolic advantage of reducing diets. Metab Syndr Rel Disord 2003, I:209-219.

4. Feinman RD, Fine EJ: "A calorie is a calorie" violates the second law of thermodynamics. Nutr J 2004, 3(I):9.

5. Boden G, Sargrad K, Homko C, Mozzoli M, Stein TP: Effect of a lowcarbohydrate diet on appetite, blood glucose levels, and insulin resistance in obese patients with type 2 diabetes. Ann Intern Med 2005, I 42(6):403-4I I.

6. Larosa JC, Fry AG, Muesing R, Rosing DR: Effects of high-protein, low-carbohydrate dieting on plasma lipoproteins and body weight. J Am Diet Assoc 1980, 77(3):264-270.

7. Hauner H, Meier M, Jockel KH, Frey UH, Siffert W: Prediction of successful weight reduction under sibutramine therapy through genotyping of the G-protein beta3 subunit gene (GNB3) C825T polymorphism. Pharmacogenetics 2003, 13(8):453-459.

8. Masuo K, Katsuya T, Kawaguchi H, Fu Y, Rakugi H, Ogihara T, Tuck ML: Rebound weight gain as associated with high plasma norepinephrine levels that are mediated through polymorphisms in the beta2-adrenoceptor. Am J Hypertens 2005, I8(II): I508-15I6.

9. Sparrow CP, Burton CA, Hernandez M, Mundt S, Hassing $\mathrm{H}$, Patel S, Rosa R, Hermanowski-Vosatka A, Wang PR, Zhang D, Peterson L, Detmers PA, Chao YS, Wright SD: Simvastatin has anti-inflammatory and antiatherosclerotic activities independent of plasma cholesterol lowering. Arterioscler Thromb Vasc Biol 200I, 2I(I):115-121.

10. Shiwaku K, Nogi A, Anuurad E, Kitajima K, Enkhmaa B, Shimono K, Yamane $Y$ : Difficulty in losing weight by behavioral intervention for women with Trp64Arg polymorphism of the beta3adrenergic receptor gene. Int J Obes Relat Metab Disord 2003, 27(9): 1028-1036.

II. Spraggs CF, Pillai SG, Dow D, Douglas C, McCarthy L, Manasco PK, Stubbins M, Roses AD: Pharmacogenetics and obesity: common gene variants influence weight loss response of the norepinephrine/dopamine transporter inhibitor GW320659 in obese subjects. Pharmacogenet Genomics 2005, I 5(I 2):883-889.

12. Pooley EC, Fairburn CG, Cooper Z, Sodhi MS, Cowen PJ, Harrison PJ: A 5-HT2C receptor promoter polymorphism (HTR2C $759 \mathrm{C} / \mathrm{T}$ ) is associated with obesity in women, and with resistance to weight loss in heterozygotes. Am J Med Genet B Neuropsychiatr Genet 2004, I 26(1): 124-127.

13. Westberg L, Bah J, Rastam M, Gillberg C, Wentz E, Melke J, Hellstrand $M$, Eriksson E: Association between a polymorphism of the 5HT2C receptor and weight loss in teenage girls. Neuropsychopharmacology 2002, 26(6):789-793. 
14. Lindi VI, Uusitupa MI, Lindstrom J, Louheranta A, Eriksson JG, Valle TT, Hamalainen H, llanne-Parikka P, Keinanen-Kiukaanniemi S, Laakso $M$, Tuomilehto J: Association of the Prol 2Ala polymorphism in the PPAR-gamma2 gene with 3-year incidence of type 2 diabetes and body weight change in the Finnish Diabetes Prevention Study. Diabetes 2002, 5 I (8):258I-2586.

15. Vogels N, Mariman EC, Bouwman FG, Kester AD, Diepvens K, Westerterp-Plantenga MS: Relation of weight maintenance and dietary restraint to peroxisome proliferator-activated receptor gamma2, glucocorticoid receptor, and ciliary neurotrophic factor polymorphisms. Am J Clin Nutr 2005, 82(4):740-746.

16. Corella D, Qi L, Sorli JV, Godoy D, Portoles O, Coltell O, Greenberg AS, Ordovas JM: Obese subjects carrying the I I482G $>$ A polymorphism at the perilipin locus are resistant to weight loss after dietary energy restriction. J Clin Endocrinol Metab 2005, 90(9):5I2I-5I26. Epub 2005 Jun 5128

17. Takabatake N, Sata M, Inoue S, Shibata Y, Abe S, Wada T, Machiya J, Ji G, Matsuura T, Takeishi Y, Muramatsu M, Kubota I: A novel polymorphism in secretory phospholipase A2-IID is associated with body weight loss in chronic obstructive pulmonary disease. Am J Respir Crit Care Med 2005, I 72(9): I097-I I 04. Epub 2005 Jul 1097

18. Ruano GHT: Physiogenomics: Integrating systems engineering and nanotechnology for personalized health. The Biomedical Engineering Handbook 2005.

19. Volek JS, Sharman MJ: Cardiovascular and hormonal aspects of very-low-carbohydrate ketogenic diets. Obes Res 2004, I 2(Suppl 2): I |5S- |23S.

20. Volek JS, Sharman MJ, Gomez AL, Judelson DA, Rubin MR, Watson G, Sokmen B, Silvestre R, French DN, Kraemer WJ: Comparison of energy-restricted very low-carbohydrate and low-fat diets on weight loss and body composition in overweight men and women. Nutr Metab (Lond) 2004, I ( I): I3

21. Volek JS, Sharman MJ, Gomez AL, Scheett TP, Kraemer WJ: An isoenergetic very low carbohydrate diet improves serum HDL cholesterol and triacylglycerol concentrations, the total cholesterol to HDL cholesterol ratio and postprandial pipemic responses compared with a low fat diet in normal weight, normolipidemic women. J Nutr 2003, I33(9):2756-276I.

22. Wood RJ, Volek JS, Liu Y, Shachter NS, Contois JH, Fernandez ML: Carbohydrate Restriction Alters Lipoprotein Metabolism by Modifying VLDL, LDL, and HDL Subfraction Distribution and Size in Overweight Men. J Nutr 2006, I 36(2):384-389.

23. Fan JB, Oliphant A, Shen R, Kermani BG, Garcia F, Gunderson KL, Hansen M, Steemers F, Butler SL, Deloukas P, Galver L, Hunt S, McBride C, Bibikova M, Rubano T, Chen J, Wickham E, Doucet D, Chang W, Campbell D, Zhang B, Kruglyak S, Bentley D, Haas J, Rigault $P$, Zhou L, Stuelpnagel J, Chee MS: Highly parallel SNP genotyping. Cold Spring Harb Symp Quant Biol 2003, 68:69-78.

24. Oliphant A, Barker DL, Stuelpnagel JR, Chee MS: BeadArray technology: enabling an accurate, cost-effective approach to high-throughput genotyping. Biotechniques 2002:56-58. 60-5 I

25. Dalgaard P: Introductory Statistics with R. Springer 2002

26. Faraway J]: Linear Models with R. Boca Raton, FL: Chapman \& Hall/CRC; 2004.

27. Maindonald J, Braun J: Data Analysis and Graphics Using R. Cambridge: Cambridge University Press; 2003.

28. Benjamini $Y$, Hochberg $Y$ : Controlling the false discovery rate: $a$ practical and powerful approach to multiple testing. Journal of the Royal Statistical Society 1995:289-300.

29. Benjamini $Y$, Hochberg $Y$ : On the adaptive control of the false discovery rate in multiple testing with independent statistics. J Educ Behav Stat 2000, 25:60-83.

30. Reiner A, Yekutieli D, Benjamini Y: Identifying differentially expressed genes using false discovery rate controlling procedures. Bioinformatics 2003, I 9(3):368-375.

31. Rosner B: Fundamentals of Biostatistics. Belmont, CA: Wadsworth Publishing Co; 1995.

32. Cleveland WS: Robust locally weighted regression and smoothing scatterplots. I Am Stat Assoc 1979, 74:829-836.

33. Cleveland WS, Devlin SJ: Locally Weighted Regression: An Approach to Regression Analysis by Local Fitting. J Am Stat Assoc 1988, 83:596-610.

34. Carriere F, Grandval P, Renou C, Palomba A, Prieri F, Giallo J, Henniges F, Sander-Struckmeier S, Laugier R: Quantitative study of digestive enzyme secretion and gastrointestinal lipolysis in chronic pancreatitis. Clin Gastroenterol Hepatol 2005, 3(I):28-38.

35. Shulman GI, Rothman DL, Jue T, Stein P, DeFronzo RA, Shulman RG: Quantitation of muscle glycogen synthesis in normal subjects and subjects with non-insulin-dependent diabetes by I3C nuclear magnetic resonance spectroscopy. N Engl J Med 1990, 322(4):223-228

36. Motoyama K, Emoto M, Tahara H, Komatsu M, Shoji T, Inaba M, Nishizawa $Y$ : Association of muscle glycogen synthase polymorphism with insulin resistance in type $\mathbf{2}$ diabetic patients. Metabolism 2003, 52(7):895-899.

37. Wang C, Bai Y, Ouyang A: Polymorphism of the glycogen synthase gene and non-insulin-dependent diabetes mellitus in Chinese population. Chin Med J (Engl) I 998, I I I ( I 0):903-905.

38. Krssak M, Brehm A, Bernroider E, Anderwald C, Nowotny P, Dalla Man C, Cobelli C, Cline GW, Shulman GI, Waldhausl W, Roden M: Alterations in postprandial hepatic glycogen metabolism in type 2 diabetes. Diabetes 2004, 53(I 2):3048-3056.

39. Tall AR: An overview of reverse cholesterol transport. Eur Heart ] 1998, I 9(Suppl A):A3 I-35.

40. Volek JS, Sharman MJ, Forsythe CE: Modification of lipoproteins by very low-carbohydrate diets. J Nutr 2005, I 35(6): I 339-I 342.

4I. Heilbronn LK, Noakes M, Clifton PM: Association between HDLcholesterol and the Taq IB polymorphism in the cholesterol ester transfer protein gene in obese women. Atherosclerosis 2002, I 62(2):419-424

42. Schauble N, Reichwald K, Grassl W, Bechstein H, Muller HC, Scherag A, Geller F, Utting M, Siegfried W, Goldschmidt H, Blundell J, Lawton C, Alam R, Whybrow S, Stubbs J, Platzer M, Hebebrand J, Hinney A: Human galanin (GAL) and galanin I receptor (GALRI) variations are not involved in fat intake and early onset obesity. J Nutr 2005, I 35(6): I 387-1392.

43. Leibowitz SF: Regulation and effects of hypothalamic galanin: relation to dietary fat, alcohol ingestion, circulating lipids and energy homeostasis. Neuropeptides 2005, 39(3):327-332.

44. Ruano G, Thompson PD, Windemuth A, Smith A, Kocherla M, Holford TR, Seip R, Wu AH: Physiogenomic analysis links serum creatine kinase activities during statin therapy to vascular smooth muscle homeostasis. Pharmacogenomics 2005, 6(8):865-872.
Publish with Biomed Central and every scientist can read your work free of charge

"BioMed Central will be the most significant development for disseminating the results of biomedical research in our lifetime. "

Sir Paul Nurse, Cancer Research UK

Your research papers will be:

- available free of charge to the entire biomedical community

- peer reviewed and published immediately upon acceptance

- cited in PubMed and archived on PubMed Central

- yours - you keep the copyright 